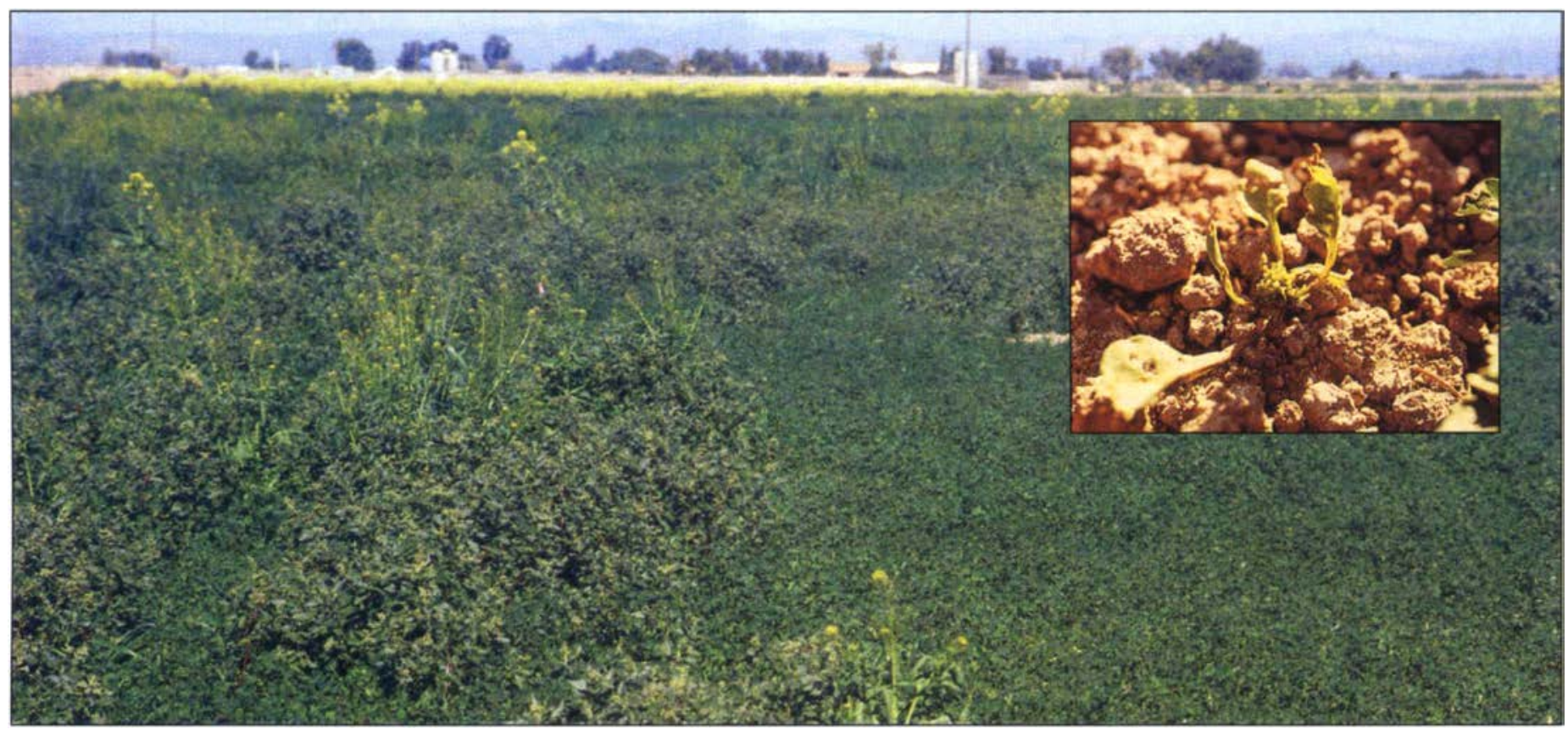

Imazethapyr plantback study, treated plot on right. Inset shows the effect of imazethapyr on sugarbeet plant. Note stunted new leaves in center of plant; the photo was taken about 20 months after treatment.

\title{
After 2 years, imazethapyr residues have no effect on crops in Imperial Valley
}

\author{
Carl E. Bell a Brent E. Boutwell
}

A study was conducted in the Imperial Valley to determine the effect of soil residues on subsequent rotational crops after the herbicide imazethapyr is applied to alfalfa. Imazethapyr's label recommends a plantback interval of up to $\mathbf{4 0}$ months for sugarbeet and most rotational crops grown in this region. Wheat, lettuce, cotton, tomato and cantaloupe yields were not reduced by imazethapyr. Broccoli, carrot, sugarbeet and sudangrass yields were lower in imazethapyr plots when these crops were sown 11 months after treatment. But after 2 years, soil residues at the maximum-allowed application rate had no effect on any of the rotational crops we studied. Therefore, imazethapyr's plantback recommendations may be too conservative for crops grown in rotation with alfalfa in the Imperial Valley.
Imazethapyr (Pursuit) is a relatively new herbicide that has gained widespread use in California alfalfa crops since its registration in 1996. It has been very effective for control of annual broadleaf weeds in seedling alfalfa without causing injury to the crop. A disadvantage associated with imazethapyr, however, is its lengthy persistence in the soil. Some crops grown in rotation with alfalfa are very sensitive to this herbicide and can be injured when planted 1, 2 or more years after an application. Sugarbeet, in particular, can be injured or killed by soil residual levels of imazethapyr as low as one part per billion.

Alfalfa is the most common crop in the Imperial Valley, typically occupying $35 \%$ to $40 \%$ of the farmland. Because alfalfa is planted in the fall, winter annual broadleaf species are the most common weeds in the seedling stand. Imazethapyr has become a popular herbicide in this area because it is effective against most winter an- nuals, especially some previously hard-to-control weeds such as little mallow and members of the mustard family (Brassicaceae).

In the Imperial Valley, rotational schemes generally utilize alfalfa as the basic component. Other crops included in these rotations are wheat, sugarbeet, sudangrass and a wide range of winter and spring vegetables. This mix of crops, frequent rotations, and the inclusion of alfalfa in most rotations creates a plantback concern. Plantback refers to the time span between the application of a pesticide and when it is safe to plant a rotational crop without fear of injury to the plant.

\section{Plantback recommendations}

The imazethapyr label contains a series of recommendations regarding plantback intervals. The shortest of these intervals is zero months in the case of other legumes, such as beans and peanuts, and up to 40 months for crops not listed. Nonlisted crops in- 
TABLE 1. Chronology of important events and activities during a study of imazethapyr's effect on rotational crops after application to alfalfa in the Imperial Valley

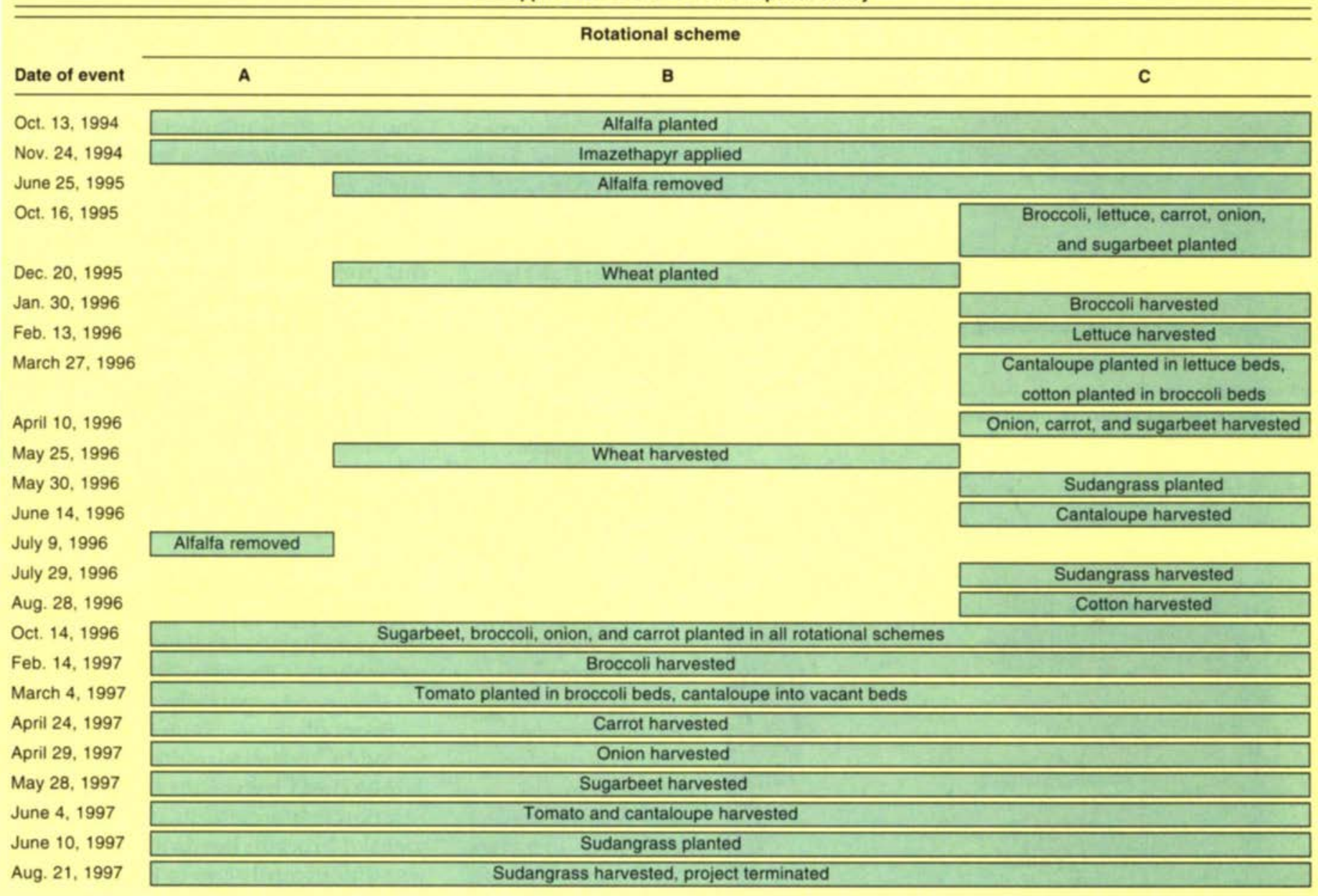

clude sugarbeet and most of the vegetables grown in the Imperial Valley.

These recommendations were not, however, developed in Southern California. Soil persistence of this herbicide is affected by many factors, such as soil type, soil $\mathrm{pH}$, irrigation or moisture regimes, and farming practices. Conversations with research representatives of imazethapyr's manufacturer and with other weed scientists suggested that the label recommendations on plantback were probably inaccurate for the Imperial Valley. Research with imazethapyr has shown that a high soil $\mathrm{pH}$ of 8.0 or greater would result in more rapid soil degradation of imazethapyr than would occur in acid soils.

Soils in arid regions of California such as the Imperial Valley typically have $\mathrm{pHs}$ between 7.5 and 8.5 . Our concern was that plantback restrictions on the Pursuit label were too conservative and longer than necessary. We knew of growers who had wanted to plant a crop before the recommended plantback period expired. In the Imperial Valley, the typical time span from treatment of seedling alfalfa with imazethapyr, through the life of the alfalfa crop, to the planting of a rotational crop is 34 months. The recommended 40-month plantback interval would present a problem, especially in the case of sugarbeet and vegetable crops.

\section{Alfalfa rotational crops studied}

Therefore, we conducted a plantback study in the Imperial Valley with crops commonly grown in rotation with alfalfa. This study was conducted from 1994 through 1997 at the UC Desert Research and Extension Center near Holtville. We followed typical farming practices and rotational schemes as much as possible, except that we avoided soil tillage activities such as plowing that would tend to dilute or hasten the degradation of imazethapyr. The goal was to create the "worst case scenario" for soil persistence of this herbicide.

The study began in October 1994 with planting of the alfalfa. A 3.2-acre area at the Center was divided into nine sections, each 50 feet by 260 feet, separated by raised irrigation borders. Alfalfa (cv. CUF101) was sown on flat ground between the borders at 25 pounds per acre on Oct. 13 and flood irrigated for germination the next day. The experimental design was a split plot with rotational scheme as the main plot factor and imazethapyr rate as the subplot factor.

There were three rotational schemes: (A) alfalfa for 2 years followed by rotational crops, (B) alfalfa for 1 year followed by wheat and then by rotational crops, and (C) alfalfa for 1 year followed by rotational crops (table 1). All of these schemes exposed rotational crops to soil residues of imazethapyr sooner than normal since alfalfa is usually a 3-year crop in this area. 


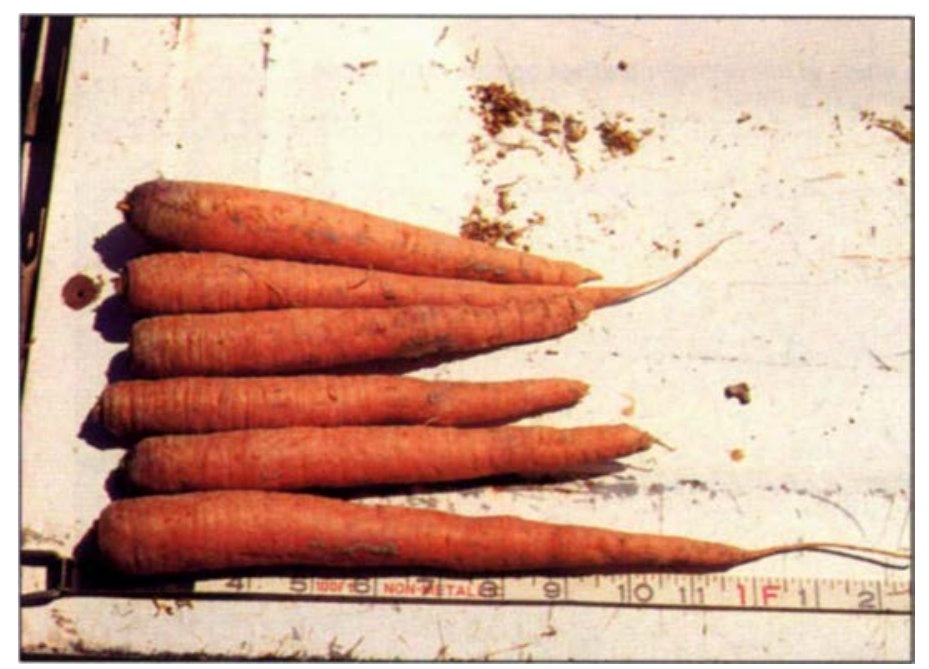

Carrots harvested about 15 months after treatment. Untreated are shown above and label rate of imazethapyr are below.

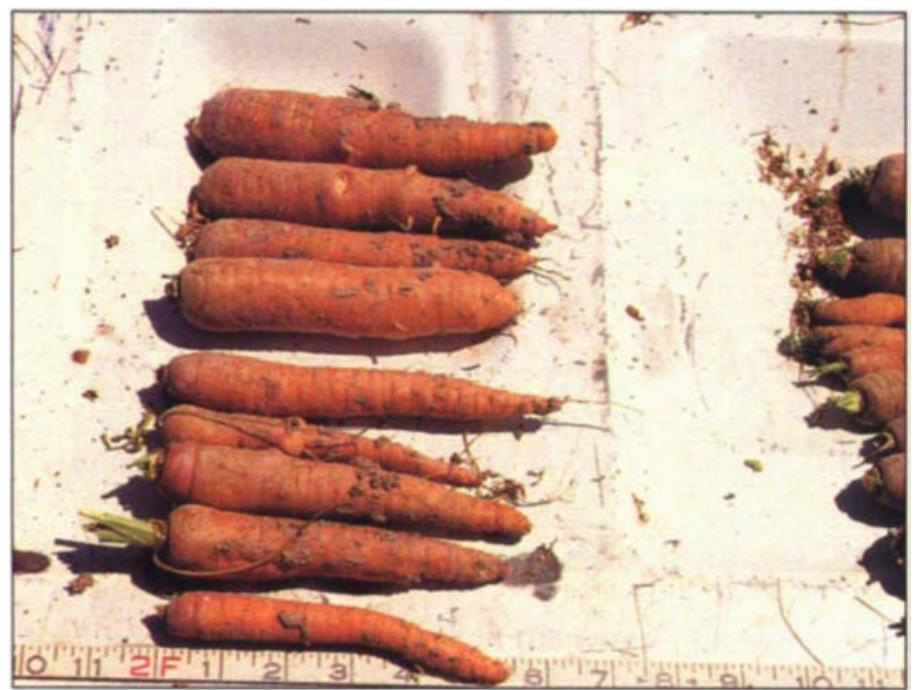

Imazethapyr treatments included an untreated control; the maximum label rate (1X) of 0.094 pounds active ingredient per acre (lb ai/A); and double this maximum rate $(2 \mathrm{X})$ or $0.188 \mathrm{lb}$ ai / A. There were three replications; main plots were randomized within three blocks and imazethapyr treatments were randomized within each main plot. The subplot size was 80 feet by 50 feet to provide room for multiple plantback crops.

Imazethapyr was applied once in this experiment, on Nov. 24, 1994, when the alfalfa was in the trifoliate stage of growth. Weed control was nearly $100 \%$ effective from this application, but there was some temporary (and typical) chlorosis and stunting of the crop. Weeds present at the time of application were London rocket (Sisymbrium irio), nettleleaf goosefoot (Chenopodium murale), common lambsquarters (Chenopodium album), little mallow (Malva parviflora) and littleseed canarygrass (Phalaris minor). The alfalfa crop was irrigated and harvested according to normal practice in this area through spring 1995.

In summer 1995 , the alfalfa was taken out of rotational schemes B and C by disking to prepare the soil for rotational crops planted later in the year. In scheme B, durum wheat (cv. Yavaros) was sown with a drill on Dec. 20, 1995, about 13 months after treatment (MAT) with imazethapyr, and flood irrigated for germination. For scheme $C$, we made raised beds 40 inches wide in each replication. There was room for 15 beds within each 50 -foot-wide main plot. Sugarbeet, broccoli, onion, carrot and lettuce were sown on Oct. 16, 1995, 11 MAT. Each crop was grown on three beds, and yield data were taken from the middle bed while the other two served as buffers from the adjacent crops. Cantaloupe was planted in rotation with lettuce, and cotton in rotation with broccoli, both $16 \mathrm{MAT}$, after harvest in the spring. Later in the spring, sudangrass was sown $18 \mathrm{MAT}$ on beds in rotation with onions.

We removed alfalfa from rotational scheme A in summer 1996 and prepared the soil for planting rotational crops in fall 1996. On Oct. 14, 1996, 23 MAT, sugarbeet, broccoli, onion and carrot were sown on 12 of the raised beds in all three rotational schemes (three beds were left unplanted) in the same fashion as in 1995. Lettuce was not included because there was no detectable effect from soil residues of imazethapyr on lettuce during the previous season. Tomatoes were transplanted in rotation with broccoli in spring 1997, 27 MAT. Cantaloupe was sown into the unplanted beds at the same time. Sudangrass was again sown, $29 \mathrm{MAT}$, in rotation with onions in late spring. With the harvest of the sudangrass in August 1997, 32 MAT, this project was concluded. Yield data analysis included Analysis of Variance (ANOV), split-plot ANOV, and linear regression.

\section{Several crops unaffected}

Several crops were apparently unaffected by imazethapyr residues in the soil, even at a rate twice the maximum allowed on the label (table 2). These included wheat, lettuce, tomato, cantaloupe and cotton. The onion stand was too variable to collect reliable yield data, so these results were not included. The other affected crops are discussed separately.

Broccoli. Broccoli yield was affected by imazethapyr when planted 11 MAT and harvested 14 MAT in rotational scheme $C$ in 1995-96. The yield of broccoli heads at the $2 X$ rate was significantly lower than the untreated control. The broccoli grown in the $1 X$-rate plot appeared to be affected by the imazethapyr, even though yield of broccoli heads was not statistically lower than in the untreated control.

Early in the season when the broccoli was small, plants in the $1 \mathrm{X}$ plots were visibly stunted compared to the untreated control. During harvest, we found the stems very woody below the head and difficult to cut with standard harvesting knives. When broccoli was planted 23 MAT and harvested 27 MAT in rotational schemes $A, B$ and $C$, the effect of imazethapyr was still apparent at the $2 X$ rate in schemes $A$ and $B$, but no longer at the $1 X$ rate.

Carrot. The effect of imazethapyr on carrots was similar to broccoli. When planted 11 MAT and harvested 17 MAT, yield at the $2 X$ rate was significantly lower than the untreated control. Although the ANOV did not detect a yield difference between the $1 \mathrm{X}$ rate and the untreated control, the carrots were shorter than those grown 
in untreated plots and had some woodiness similar to the broccoli. The effect of imazethapyr on carrot yield was not statistically significant during the second year of this project, although we still encountered some stunted carrots.

Sugarbeet. Sugarbeet is the crop regarded as most susceptible to plantback injury from imazethapyr. In this study, the $1 \mathrm{X}$ rate of imazethapyr reduced the yield of sugarbeet planted $11 \mathrm{MAT}$ and harvested 17 MAT by more than $95 \%$ compared to the untreated control. Sugarbeet symptoms of imazethapyr injury included stunting, chlorosis and distorted meristematic budding. There was no effect on sugarbeet from the $1 \mathrm{X}$ treatment when the crop was planted 23 MAT in all rotational schemes. The $2 \mathrm{X}$ rate left enough imazethapyr in the soil to cause some injury to sugarbeet.

Sudangrass. During the first year of the plantback, when sudangrass was planted $18 \mathrm{MAT}$, yield was severely reduced by both the $1 \mathrm{X}$ and the $2 X$ rates of imazethapyr. The crop was visibly stunted throughout the growing period. However, the crop planted 29 MAT did not show any symptoms and there was no effect on yield.

\section{Weed sensitivity differs}

When the rotational crops germinated in fall 1995, the species of weeds appeared to sort themselves out according to the imazethapyr treatment rate. The untreated control plots were dominated by London rocket, while the $1 \mathrm{X}$ plots were infested principally with nettleleaf goosefoot and the $2 \mathrm{X}$ plots were covered with common lambsquarters. These weeds are sensitive to imazethapyr in this same order, with London rocket very sensitive, nettleleaf goosefoot somewhat tolerant, and common lambsquarters very tolerant. It was impossible to discern from this experiment whether the differing levels of each weed were the result of soil residues inhibiting germination or of seed production related to weed control from the herbicide application a year earlier.

Yields in rotational scheme A were lower for most crops than the other schemes, although the differences
TABLE 2. Rotational crop yield in tons/acre as affected by imazethapyr rate and rotational scheme

\begin{tabular}{|c|c|c|c|c|}
\hline \multirow[b]{3}{*}{ Crop/imazethapyr rate } & $1995-96$ & \multicolumn{3}{|c|}{$1996-97$} \\
\hline & \multicolumn{4}{|c|}{ Rotational scheme } \\
\hline & C & A & B & C \\
\hline \multicolumn{5}{|l|}{ Ib aivacre } \\
\hline \multicolumn{5}{|l|}{ Broccoli } \\
\hline 0 & 9.5 & 9.0 & 9.7 & 9.5 \\
\hline 0.094 & 7.2 & 8.2 & 9.7 & 10.5 \\
\hline 0.188 & 2.6 & 5.7 & 6.6 & 9.9 \\
\hline $\operatorname{LSD}(0.05)$ & 3.7 & 3.3 & me, & oyr rate \\
\hline
\end{tabular}

\begin{tabular}{|c|c|c|c|c|}
\hline \multicolumn{5}{|l|}{ Lettuce } \\
\hline 0 & 21.8 & \multicolumn{3}{|c|}{ Not grown in 1996-97 } \\
\hline 0.094 & 23.8 & & & \\
\hline 0.188 & 24.4 & & & \\
\hline $\operatorname{LSD}(0.05)$ & n.s. & & & \\
\hline \multicolumn{5}{|l|}{ Carrot } \\
\hline 0 & 21.6 & 17.7 & 20.5 & 26.9 \\
\hline 0.094 & 19.4 & 17.2 & 21.4 & 25.4 \\
\hline 0.188 & 10.5 & 15.1 & 20.5 & 27.7 \\
\hline $\operatorname{LSD}(0.05)$ & 7.8 & \multicolumn{3}{|c|}{ n.s. for rotational scheme and for imazethapyr rate } \\
\hline \multicolumn{5}{|l|}{ Cantaloupe } \\
\hline 0 & 4.4 & 12.2 & 12.2 & 10.7 \\
\hline 0.094 & 5.2 & 10.7 & 10.0 & 10.8 \\
\hline 0.188 & 3.4 & 7.2 & 8.5 & 11.0 \\
\hline $\operatorname{LSD}(0.05)$ & n.s. & \multicolumn{3}{|c|}{ n.s. for rotational scheme and for imazethapyr rate } \\
\hline \multicolumn{5}{|l|}{ Sugarbeet } \\
\hline 0 & 51.2 & 35.3 & 39.6 & 40.6 \\
\hline 0.094 & 2.3 & 35.6 & 39.5 & 44.9 \\
\hline 0.188 & 3.0 & 15.3 & 33.8 & 35.5 \\
\hline $\operatorname{LSD}(0.05)$ & 8.2 & \multicolumn{3}{|c|}{ n.s. for rotational scheme, 18.9 for imazethapyr rate } \\
\hline
\end{tabular}

\begin{tabular}{|c|c|c|c|c|}
\hline \multicolumn{5}{|l|}{ Cotton } \\
\hline 0 & 21.8 & \multirow{4}{*}{\multicolumn{2}{|c|}{ Not grown in 1996-97 }} & \\
\hline 0.094 & 23.8 & & & \\
\hline 0.188 & 24.4 & & & \\
\hline $\operatorname{LSD}(0.05)$ & n.s. & & & \\
\hline \multicolumn{5}{|l|}{ Wheat } \\
\hline 0 & 1.8 & \multicolumn{3}{|c|}{ Not grown in 1996-97 } \\
\hline 0.094 & 1.7 & & & \\
\hline 0.188 & 1.7 & & & \\
\hline $\operatorname{LSD}(0.05)$ & n.s. & & & \\
\hline \multicolumn{5}{|l|}{ Tomato } \\
\hline 0 & Not grown in 1995-96 & 11.0 & 12.0 & 11.0 \\
\hline 0.094 & & 9.7 & 10.2 & 13.3 \\
\hline 0.188 & & 3.6 & 9.5 & 10.8 \\
\hline $\operatorname{LSD}(0.05)$ & & \multicolumn{3}{|c|}{ n.s. for rotational scheme and for imazethapyr rate } \\
\hline \multicolumn{5}{|l|}{ Sudangrass } \\
\hline 0 & 4.0 & 10.5 & 10.8 & 10.1 \\
\hline 0.094 & 1.3 & 9.7 & 9.8 & 10.6 \\
\hline 0.188 & 0.4 & 9.9 & 10.1 & 10.8 \\
\hline $\operatorname{LSD}(0.05)$ & 2.4 & \multicolumn{3}{|c|}{ n.s. for rotational scheme and for imazethapyr rate } \\
\hline
\end{tabular}

"No significant differences between treatments $(P=0.05)$ 
were not significant (table 2). There were large differences in the yield data for carrot and sugarbeet. Soil analysis was conducted on each plot to see if there was an explanation related to salinity or soil texture. Replications of the three rotational schemes were in three blocks, each consisting of three plots receiving different herbicide treatments, and salinity levels in one block were generally higher than the other two. The first block had an average electrical conductivity (e.c., a measure of salinity) of 4.4 decisiemens per meter (dS/m), compared to $2.9 \mathrm{dS} / \mathrm{m}$ for block two and 3.9 for block three. We suspect that the salinity differences caused the apparent differences between rotational schemes.

\section{No threat after 2 years}

Under normal use rates and farming practices in the Imperial Valley, we found that imazethapyr did not pose a serious threat to rotational crops 2 years after application. The current label wording allows farmers to plant rotational crops in shorter intervals than recommended, but all liability for crop injuries is assumed by the grower. Based upon the results of this study, we feel that shortening the rotational period to 2 years is safe, assuming conditions are similar to ours. The results should also pertain to other agricultural valleys in the Lower Colorado River Desert.

\section{C.E. Bell is Weed Science Farm Advisor} and B.E. Boutwell is Staff Research Associate II, UC Cooperative Extension, Imperial County. The authors thank American Cyanamid Company for funding this research.

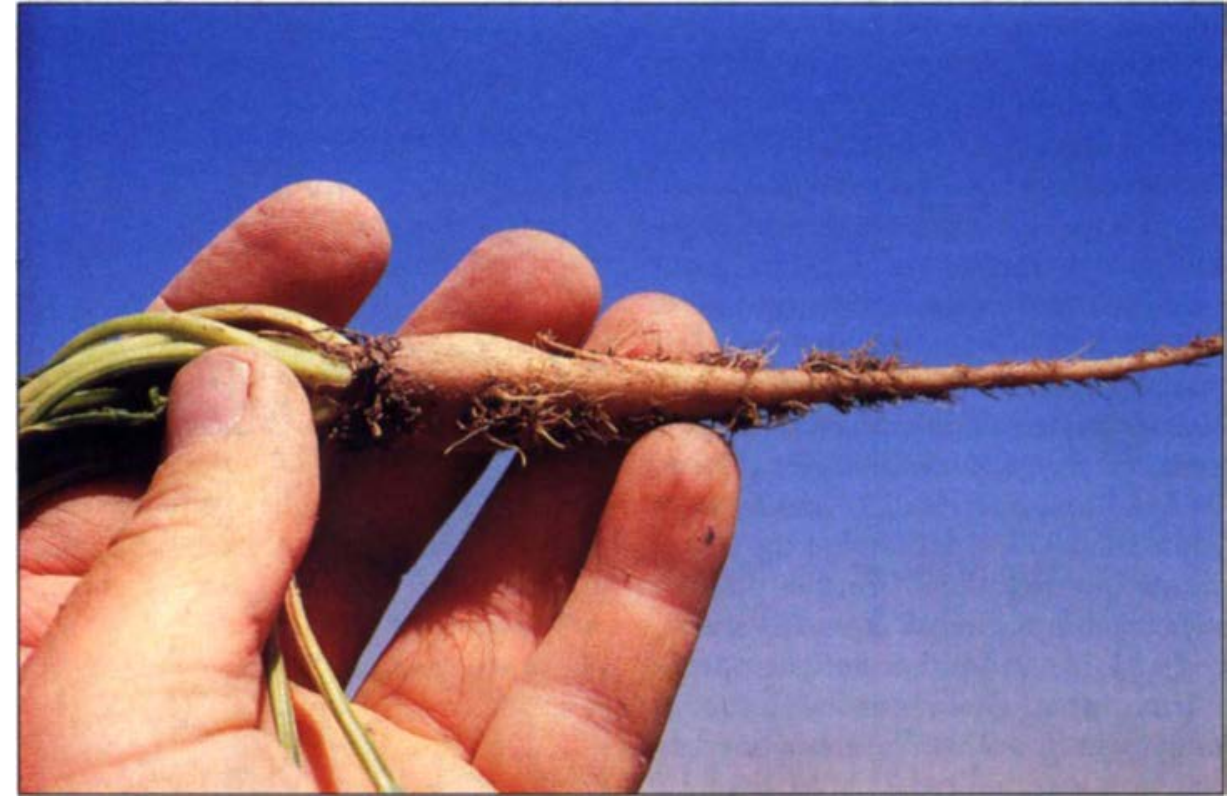

The effect of imazethapyr at label rate on sugarbeets planted 11 months after treatment and harvested 18 months after treatment was observed. Below, a sugarbeet from an untreated plot planted and harvested at the same time as the one above.

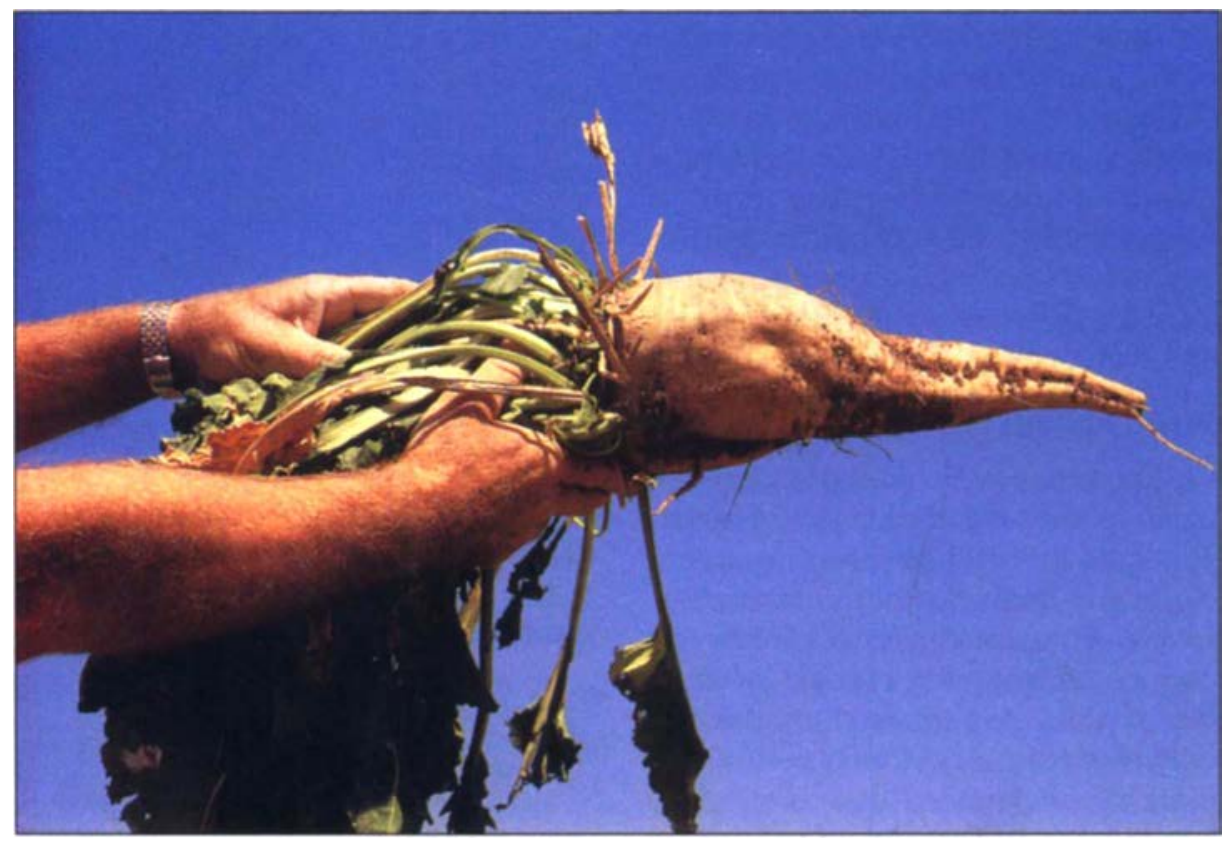

\section{CALIFORNIA AGRICULTURE ASSOCIATE EDITORS}

Animal, Avian, Aquaculture
\& Veterinary Sciences
Jim Cullor
Christopher M. Dewees
Kathryn Radke
Barbara A. Reed
Economics \& Public Policy
George Goldman
Richard A. Howitt
Alvin Sokolow
Food \& Nutrition
Amy Block Joy
Eunice Williamson

Human \& Community Development

Linda M. Manton

Karen P. Varcoe

Land, Air \& Water Sciences John Letey

Henry J. Vaux, Jr.

Natural Resources

Daniel W. Anderson

Lynn Huntsinger

Richard B. Standiford
Pest Management

Michael K. Rust

Robert Washino

Plant Sciences

Jodie S. Holt

Lee F. Jackson

G. Steven Sibbett http://danr.ucop.edu/calag/

CALAG@ucop.edu

PH: 510 987-0044

FAX: $510465-2659$ 